\title{
Repositioning of Overerupted Upper Molar for Facilitating Lower Implant Placement with Miniscrews
}

\author{
Shafira Kurnia, Samuel Rehuel Santoso, Widyawati Sutedjo and Chiquita Prahasanti \\ Department of Periodontology, Faculty of Dental Medicine, Universitas Airlangga, Surabaya, Indonesia
}

\begin{abstract}
Loss of the mandibular first molar often leads to the overeruption of the opposing maxillary first molar, resulting in inadequate interocclusal space. In this report, two miniscrews were placed into the buccal and palatal region of the upper first molar to correct the overerupted teeth using power chains. Progress of treatment was evaluated every two weeks for five months. The clinical results showed significant intrusion while maintaining periodontal health, tooth vitality, and root length.
\end{abstract}

Key Words: overerupted molar, intrusion, miniscrew

\section{INTRODUCTION}

The loss of mandibular first molar can lead to serious problems with remarkable clinical changes in the position of adjacent and antagonist teeth; this may require orthodontic and rehabilitation treatment due to the complexity of the resulting malocclusion. Overeruption was statistically greater in maxillary unopposed teeth than in mandibular unopposed teeth. ${ }^{1,2}$ The maxillary molar overeruption often causes difficulties upon treating antagonist tooth prostheses.

The use of orthodontic miniscrew for molar intrusion to re-establish a functional posterior occlusion is an option compared to enameloplasty, intentional root canal treatment, and surgical impaction. ${ }^{3}$ This case report describes a method for regaining of vertical space by an intrusion of upper left first maxillary molar using orthodontic miniscrews and power chains for antagonist implant crown restoration.

\section{CASE REPORT}

The patient was a 42-year-old woman who came to University of Airlangga Oral and Dental Hospital with the complaint of missing lower left molars since a year ago. The extruded antagonist upper first molar (26) filled the space of the lower left first molar. The loss of interocclusal space was about $3 \mathrm{~mm}$ in the buccal cusp and $4 \mathrm{~mm}$ in the palatal cusp (Figure 1). The 26 tooth was sound and the periodontal

Paper presented at the Joint Scientific Meeting in Special Care Dentistry, July 5, 2019, Amerta Room, 4th Floor, main campus of Universitas Airlangga, Surabaya, Indonesia.

Corresponding author: Chiquita Prahasanti

Department of Periodontology

Faculty of Dental Medicine

Universitas Airlangga

J. Mayjen. Prof. Dr. Moestopo No. 47 Surabaya 60132 - Indonesia

Email: chiquita-p-s@fkg.unair.ac.id tissue condition was normal. Patient had a good oral hygiene and low risk caries. Patient gave her written consent after having been informed about the condition, procedures, complication, and prognosis for this treatment.

The purpose of this treatment was to carry out the intrusion of maxillary left first molar using orthodontic miniscrew, to provide an adequate space for mandibular prosthetic replacement of the left first molar. The first 


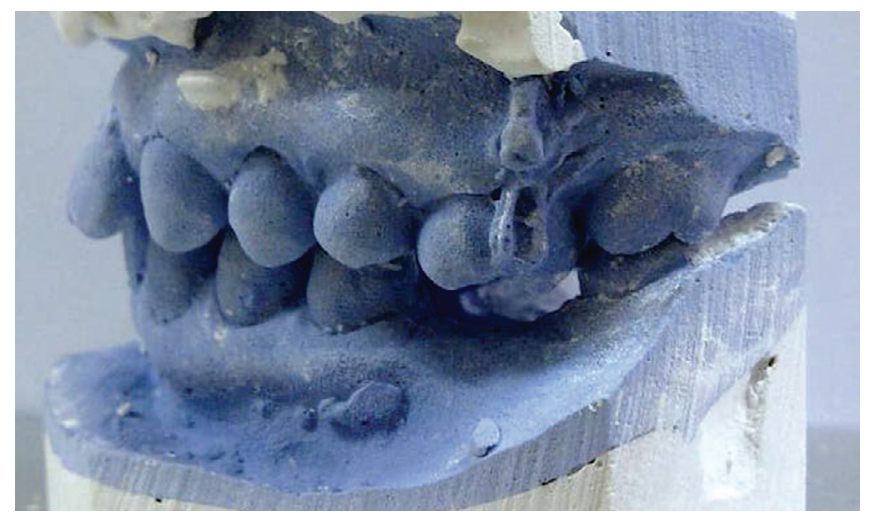

Figure 1. An inadequate interocclusal space as a result of an overeruption of maxillary molar.

miniscrew with a $\varnothing 1.0 \mathrm{~mm}$ and $10 \mathrm{~mm}$ in length was mounted into the buccal alveolar bone of the left upper jaw, between the distal premolar and mesial maxillary first molar. In the palatal section the maxillary first molar teeth were $\varnothing 1.0 \mathrm{~mm}$ and $10 \mathrm{~mm}$ in length (Figure 2). Permanent implant with $\varnothing 4.8 \mathrm{~mm}$ and $10 \mathrm{~mm}$ in length were placed in the mandibular left first molar.

After the placement of the miniscrews, orthodontic brackets were placed in the buccal part of the first molar and maxillary second premolar followed by the installation of ligature wire. Power chains were placed on both sides of miniscrews to provide an intrusion force for maxillary first molar (Figure 3). The power chain was replaced every 2 weeks. After 5 months from the first activation, the maxillary first molar had been placed on the desired position so that the fixed crown was placed on the left lower first molar. Periodontal status of 26 and adjacent teeth was checked every visit and showed no sign of inflammation.

After the intrusion, the first maxillary molar was in position in the desired place to provide an adequate interocclusal space. The implant abutment was placed on lower mandibular molar region. Figure 4 shows the final position of 26 tooth with the regained vertical space after the intrusion treatment. The probing depth was normal at the last visit of intrusion procedure.

\section{DISCUSSION}

Overerupted teeth often become a problem when restoring the antagonist teeth. The needed vertical space for abutment for dental implant is dependent on the manufactured dental implant abutment and the occlusal surface thickness of the crown. An inadequate space could be treated using various methods. Enameloplasty can be
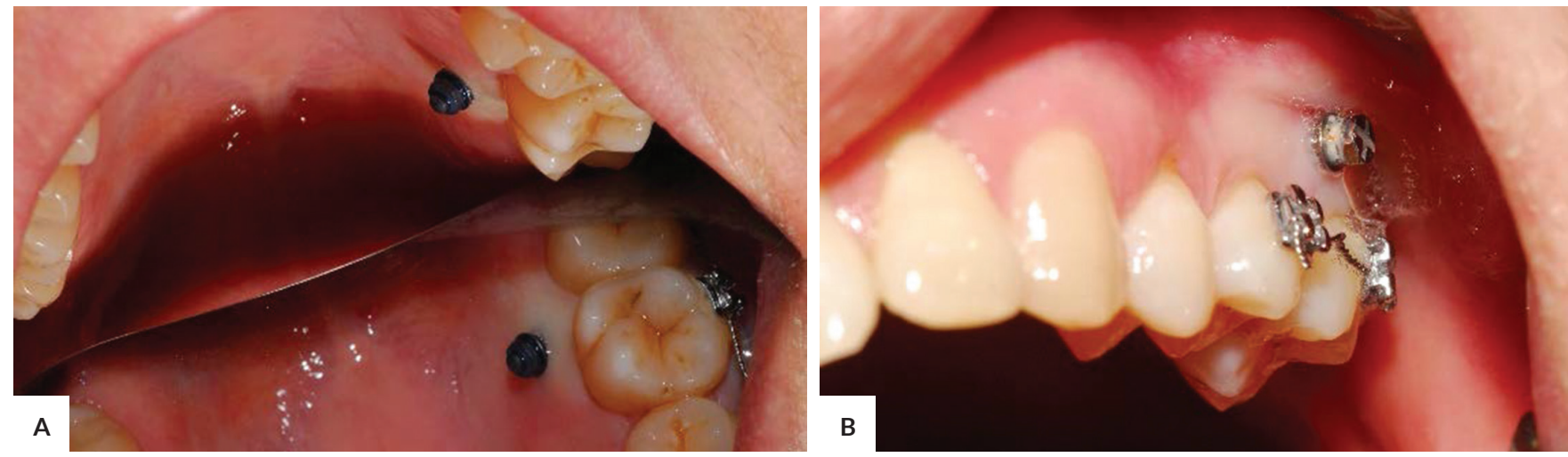

Figure 2. (A) A palatal placement of miniscrew. (B) A buccal placement of miniscrew with two orthodontic brackets on first molar and second premolar.

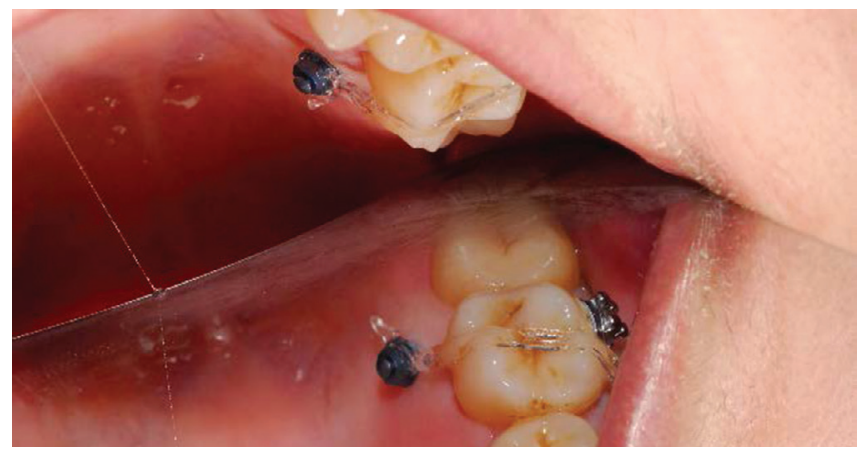

Figure 3. Power chains with miniscrews.

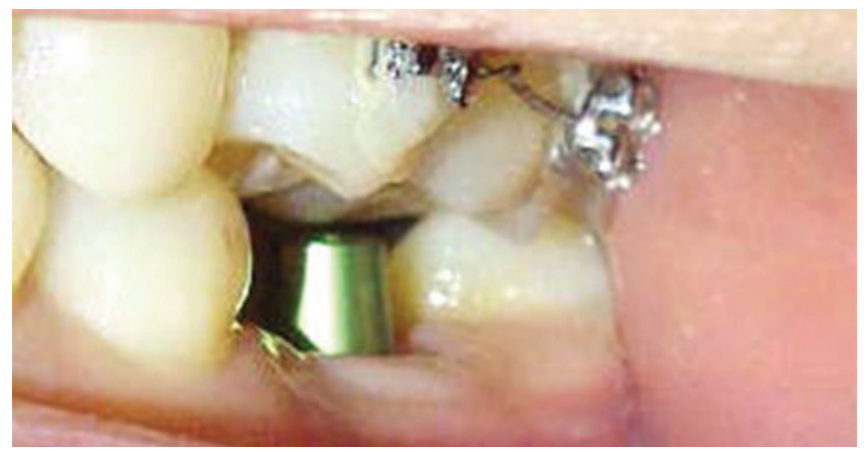

Figure 4. An adequate interocclusal space for mandibular first molar replacement crown. 
used to regain $1-2 \mathrm{~mm}$ interocclusal space by grinding the cusp. Root canal therapy should be performed on hyperovererupted vital tooth since the excessive removal of the tooth structure is needed. When the space involves dentoalveolar extrusion, orthognathic surgical procedures could be performed using posterior segmental osteotomy method. Molar intrusion using orthodontic temporary anchorage devices (TADs) are used to regain the space by intruding the tooth. ${ }^{3}$

The condition in this patient was an inadequate interocclusal space of $3 \mathrm{~mm}$ in the buccal cusp and $4 \mathrm{~mm}$ in the palatal cusp. The procedure of using root canal therapy for excessive grinding of 26 was not used as the tooth structure is sound. As we considered to preserve the tooth structure and vitality, as in this case, we used an orthodontic TADs to regain the interocclusal space. The intrusion for maxillary molars can be achieved within five months using two miniscrews as temporary skeletal anchorage.

The consideration for placement of miniscrews was based on the quality and quantity of bone density and adjacent anatomical structures. In this case, bilateral intrusive force was used to prevent buccal or palatal tipping in molar tooth. The miniscrews were placed on the paramedian areas and interdental buccal areas. Palatal paramedian areas have been recommended for placement of miniscrew in adult patients because of the thin keratinized soft tissue, compact bone, and a safe distance from the palatinal artery. ${ }^{4-6}$ The maxilla and interdental tuberosity regions are also an option as safe and easy areas for miniscew placement. ${ }^{7}$ For miniscrew which is placed in the interdental buccal area, the distance of $2 \mathrm{~mm}$ between the miniscrew and adjacent tooth roots is necessary to prevent root damage. ${ }^{8}$

Al-Falahi, et al reported that the external apical root resorption ranged from 0.34 to $0.74 \mathrm{~mm}$, which was statistically significant but not clinically significant. ${ }^{9}$

In a study conducted by Bayani S, et al in 2015, they stated that the maxillary molar intrusion treatment with miniscrew showed no significant probing depth throughout the treatment. ${ }^{10}$ However the Ghanbari, et al study showed that periodontal health was affected by the miniscrews as the plaque accumulation increased. ${ }^{11}$ Inadequate personal oral hygiene is known as one of the major risk factors for periodontitis. Oral care habits such as regular toothbrushing and dental visits can decrease the risk of periodontitis. ${ }^{12}$ The common clinical signs of plaque-induced gingivitis include erythema, edema, bleeding, tenderness, and enlargement; these should alert the patients to have their periodontal status checked. ${ }^{13,14}$ In this study, we reported that the periodontal status was good and not affected by the miniscrews placement because the patient practiced good oral hygiene.

The clinical use of TAD includes some risks, screw fracture as one of the most undesirable risk which occurs not only in placement but also in the removal. Other complications of miniscrews are screw failure, damage to the hard tissues, damage to the soft tissues, tooth movement through bone deficient areas (e.g., the maxillary sinus), and pain and discomfort after implantation. ${ }^{15}$ Contraindications for miniscrews include problematic healing, compromised immune system, bleeding disorder, pathological bone quality, and inadequate oral hygiene. Miniscrews also can be contraindicated in children with deciduous or early mixed dentition. ${ }^{16}$

Orthodontic miniscrews are simple and excellent anchorage devices, demanding less cooperation from patient and provide an opportunity for clinician to perform desired tooth movement without unnecessarily sacrificing healthy tooth structure of antagonist tooth. ${ }^{17}$ Maintaining a good oral hygiene is an important factor in orthodontic TADs, as the devices could impair the patient ability to perform a thorough oral hygiene resulting in an increase in periodontal disease risk. ${ }^{11}$ The lack of patient cooperation in maintaining hygiene in the area surrounding the screw is a limitation of this treatment. ${ }^{18}$

\section{CONCLUSION}

The maxillary molar overeruption often causes difficulties on treating antagonist teeth prostheses. The preservation of the tooth structure and vitality is important so we used an orthodontic TADs to regain the interocclusal space. The use of two orthodontic miniscrews for maxillary tooth intrusion is a simple method that can be done for regaining vertical space. The contraindications and the risks factor related to miniscrews placement should be known by the operators before using this method. Patient ability to do thorough oral hygiene is mandatory to maintain periodontal health.

\section{Statement of Authorship}

All authors participated in data collection and analysis, and approved the final version submitted.

\section{Author Disclosure}

All authors declared no conflict of interest.

\section{Funding Source}

None.

\section{REFERENCES}

1. Roslan AA, Rahman NA, Alam MK. Dental anomalies and their treatment modalities/planning in orthodontic patients. J Orthod Sci. 2018 Sep;7:16.

2. Craddock HL. Consequences of tooth loss: 2. Dentist considerations restorative problems and implications. Dent Update. 2010 Jan-Feb; 37(1):28-32.

3. Mahoorkar S, Puranik SN, Moldi A, Chowdhary R, Majge B. Management of Supra-erupted Posterior Teeth - A Review. International Journal of Dental Clinics. 2010; 2(3):27-30.

4. Wilmes B, Ludwig B, Vasudavan S, Nienkemper M, Drescher D. The T-Zone : Median vs . Paramedian Insertion of Palatal Mini-Implants. J Clin Orthod. 2016 Sep; 50(9):543-51. 
5. Kakali L, Alharbi M, Pandis N, Gkantidis N, Kloukos D. Success of palatal implants or mini-screws placed median or paramedian for the reinforcement of anchorage during orthodontic treatment: a systematic review. Eur J Orthod. 2019 Jan; 41(1):9-20.

6. Poon YC, Chang HP, Tseng YC, Chou ST, Cheng JH, Liu PH, et al. Palatal bone thickness and associated factors in adult miniscrew placements: A cone-beam computed tomography study. Kaohsiung J Med Sci. 2015 May; 31(5):265-70.

7. Machado GL. Effects of orthodontic miniscrew placement angle and structure on the stress distribution at the bone miniscrew interface A 3D finite element analysis. Saudi J Dent Res. 2014 Jul;5(2):73-80.

8. Shigeeda T. Root proximity and stability of orthodontic anchor screws. J Oral Sci. 2014 Mar; 56(1):59-65.

9. Al-Falahi B, Hafez AM, Fouda M. Three-dimensional assessment of external apical root resorption after maxillary posterior teeth intrusion with miniscrews in anterior open bite patients. Dental Press J Orthod. 2018 Nov-Dec; 23(6):56-63.

10. Bayani S, Heravi F, Radvar M, Anbiaee N, Madani AS. Periodontal changes following molar intrusion with miniscrews. Dent Res J (Isfahan). 2015 Jul-Aug; 12(4):379-85.

11. Ghanbari HO, Gharechahi M, Ghanbarzadeh M, Raankoohi AN, Dastmalchi P. Evaluation of periodontal condition in intruded molars using miniscrews. Journal of Dental Materials and Techniques. 2015 Dec; 4(4):145-52.
12. Trombelli L, Farina R, Silva CO, Tatakis DN. Plaque-induced gingivitis: Case definition and diagnostic considerations.J Periodontol. 2018 Jun; 89 Suppl 1:S46-73.

13. Handajani J, Narissi DH. The effects of Curcuma zedoaria oil on high blood sugar level and gingivitis. Dental Journal (Majalah Kedokteran Gigi). 2015 Jun; 48(2):69-73.

14. Carolina DN, Rusyanti Y, Susanto A. Comparison of salivary alphaamylase levels in gingivitis and periodontitis. Dental Journal (Majalah Kedokteran Gigi). 2017 Dec; 50(4):216-9.

15. Kuroda S, Tanaka E. Risks and complications of miniscrew anchorage in clinical orthodontics. Jpn Dent Sci Rev. 2014 Nov; 50(4):79-85.

16. Chang HP, Tseng YC. Miniscrew implant applications in contemporary orthodontics. Kaohsiung J Med Sci. 2014 Mar; 30(3):111-5.

17. Mehta PR, Bhimani RA, Badavannavar AN. Mini-implant supported Orthodontic Molar Intrusion: An Unconventional Approach for Pre-implant Prosthetics. Int J Oral Implantol Clin Res. 2017 Jan; 8(1):26-30.

18. Brézulier D, Sorel O. New perspectives on miniscrews: improving stability. J Dentofacial Anom Orthod. 2016; 19(4):406. 